\title{
Penerapan Aplikasi Penjualan E-Sembako Berbasis Android Pada Toko Rafa Untuk Meningkatkan Omset Pendapatan
}

\author{
Aris Sudianto ${ }^{*}$, Istikomah Indah Lestari2, , Muhamad Sadali ${ }^{3}$, Hamzan Ahmadi $^{4}$ \\ 1,2,3,4 Program Studi Teknik Informatika, Universitas Hamzanwadi \\ *sudianto166@gmail.com
}

\begin{abstract}
Abstrak
Maraknya kegiatan bisnis yang berbasis electronic tentunya membawa dampak yang besar bagi kehidupan masyarakat khususnya sektor perdagangan seperti yang dialami oleh Toko Rafa, terlebih saat ini dunia tengah dilanda musibah yaitu dengan adanya pandemik covid 19 yang mengharuskan masyarakat tetap tinggal dirumah dan membatasi kegiatan diluar rumah. Hal inilah yang melatarbelakangi penulis untuk membuat suatu aplikasi yang dapat memudahkan masyarakat terkhususnya ibu rumah tangga dalam memenuhi kebutuhan rumah tangganya. penelitian ini bertujuan untuk mengetahui bagaimana efektivitas adanya aplikasi berbasis electronic dalam meningkatkan pendapatan pada toko Rafa sawing. Metode yang digunakan dalam penelitian ini adalah dengan melakukan observasi langsung ke toko rafa serta melakukan wawancara terhadap pemilik toko. Dengan melakukan observasi peneliti dapat mengetahui kondisi toko baik dari segi kesediaan produk dan segi pelayanan. Dengan melakuan wawancara peneliti dapat mengetahui seluk beluk toko dari segi keuangan, kesediaan barang dan kondisi pelayanan yang diterapkan oleh Toko rafa pada saat ini. Untuk itulah peneliti mantap ingin menerapkan konsep electronic pada Toko Rafa ini dengan cara membangun Aplikasi penjualan E-sembako berbasis android pada Toko Rafa Sawing.
\end{abstract}

Kata kunci : aplikasi, ecommerce, sembako.

\begin{abstract}
The rise of based business activities electronic certainly has a big impact on people's lives, especially the trade sector as experienced by Rafa store, especially at this time the world is being hit by a disaster, namely the COVID19 pandemic which requires people to stay at home and limit activities outside the home. This is the backgroundof the author to create an application that can facilitate the community, especially housewives in meeting their household needs. This study aims to find out how the effectiveness of based applications electronic in increasing revenue at Rafa sawing stores. The method used in this study is to make direct observations to the rafa shop and conduct interviews with shop owners. By observing the researchers can find out the condition of the store both in terms of product availability and in terms of service By conducting interviews, researchers can find out the ins and outs of the store in terms of finances, availability of goods and service conditions applied by Rafa Stores at this time. For this reason, researchers are determined to apply the concept electronic to this Rafa store by building sales system E-grocery an Android based at the Rafa Sawing store.
\end{abstract}

Keywords : application, e-commerce, basic necessities.

\section{Pendahuluan}

Menyadari semakin majunya perkembangan zaman, semakin tinggi pula kebutuhan yang ingin dipenuhi oleh masyarakat, terutama dalam hal kebutuhan rumah tangga. Perkembangan teknologi juga menyebabkan sebagian besar 
sektor kehidupan ikut terbawa arus. Hal ini jugalah yang menjadi dasar pemilihan usaha dari sektor berbasis teknologi yang diharapkan dapat memberikan manfaat yang besar terhadap dunia bisnis yang kompetitif. Salah satu implementasi teknologi dalam dunia bisnis yang sangat gencar dilakukan saat ini adalah persaingan bisnis dengan menggunakan electronic commerce (ecommerce). Kehadiran E-Commerce tidaklah lepas dari perkembangan teknologi telekomunukasi yang sangat pesat saat ini. Salah satu contoh alat telekomunikasi yang sangat pesat perkembangannya saat ini adalah alat berbasis android. Android saat ini menjadi sistem operasi terpopuler di dunia, android sendiri merupakan platform terbuka (open source) bagi para pengembang (programmer) untuk membuat aplikasi. Untuk itulah penulis menggunakan sistem operasi android ini dalam pembuatan aplikasi yang diberi nama aplikasi E-sembako pada toko Rafa, yang target pasarnya adalah kalangan ibu-ibu rumah tangga. Toko Rafa merupakan toko yang bergerak dibidang penjualan berbagai sembako di Desa Sawing Kelurahan Majidi. Sistem pemasaran dan penjualan yang dilakukan saat ini oleh Toko Rafa adala sistem penjualan manual dimana para calon pembeli harus datang langsung ke toko agar bisa berbelanja sesuai kebutuhan. Tentunya dengan sistem yang seperti itu akan memakan waktu yang lama. Oleh karena itu perlu adanya sistem yang lebih efektif dibanding dengan sistem manual, untuk itu fasilitas e-commerce saat ini sangat dibutuhkan. Dengan adanya aplikasi ecommerce ini diharapkan Toko Rafa dapat memasarkan produknya secara online sehingga konsumen dapat melihat informasi dan membeli produk tanpa harus datang ke Toko Rafa secara langsung.

\section{Tinjauan Pustaka}

\subsection{PeneltianTerkait}

Penelitian ini mengacu pada beberapa penelitian yang telah dilakukan oleh beberapa peneliti sebelumnya, diantaranya adalah sebagai berikut:

- Ilham Firman Maulana pada penelitian yang diberi judul "Penerapan Firebase Realtime Database pada aplikasi E-tilang Smartphone mobile berbasis android" didapat kesimpulan bahwa aplikasi E-tilang merupakan digitalisasi dari proses manual yang mengisi data pelanggar pada lembar surat tilang. Tujuan penelitian ini adalah membuat sistem tindak pelanggar lalu lintas atau E-tilang dengan menggunakan teknologi firebase realtime database, kemudian memberikan attachment ke pelanggar berupa notifikasi melalui aplikasi E-tilang, dan membantu pihak kepolisian dalam upaya menangani pelanggar lalu lintas[1].

- Akhmad Abdul Azis dan Fitrah Satrya Fajar pada penelitiannya yang berjudul "Perancangan Aplikasi Mobile E-commerce 
Berbasis Android Pada Toko Sembako Berkah Jaya Di Era Covid-19." Dari penelitian yang dilakukan dapat ditarik kesimpulan bahwa didapatkan berbagai perancangan sistem yang dapat dikembangkan untuk membantu pelanggan toko sembako Berkah Jaya agar dapat mengetahui informasi barang dan detail barang yang diinginkan oleh pelanggan. Pembuatan aplikasi android ini menjadi salah satu solusi untuk memberikan kemudahan kepada pelanggan untuk mengetahui informasi barang ter-update setiap minggunya. Dengan adanya aplikasi ini, pelanggan dapat mengurangi resiko tertularnya wabah covid19, karena transaksi tidak dilakukan di luar rumah dan bertemu banyak orang[2].

- M.Ramaddan Julianti, Zainul Hakim, dan Taufik Ardiyan pada penelitiannya yang diberi judul "Aplikasi Pedagang Sembako Online Berbasis Android" dapat ditarik kesimpulan bahwa penulis berhasil membangun aplikasi sembako online menggunakan aplikasi android yang dapat memetakan zona wilayah pedagang sembako dimana para pedagang yang sudah terdaftar pada aplikasi tersebut dapat berjualan dalam zona wilayahnya masing-masing sehingga dapat menjual barang dagangannya ke area yang lebih luas daripada sebelumnya yang hanya kepada orang-orang yang tinggal di sekitar toko. Penulis juga berhasil membangun aplikasi menggunakan bahasa pemerograman javascript dan framework react native yang dapat digunakan penjual untuk berjualan secara online[3].

- Aris Sudianto, dan Muhamad Sadali pada penelitiannya yang diberi judul "Penerapan Aplikasi Berbasis Android Untuk Ternak Ayam Petelur Sebagai Wadah Untuk Menghubungkan Pemilik Modal Dengan Calon Peternak" dapat ditarik kesimpulan bahwa aplikasi yang telah dibuat ini memberikan kemudahan bagi paternak, dan pemodal agar bisa bekerjasama. Peternakan ayam petelur memiliki peluang yang besar karena kebutuhan akan telur ayam yang besar dilombok, akan tetapi pemanfaatan teknologi yang saat ini sanagat pesat belum digunakan secara maksimal. Untuk itulah aplikasi ini hadir memberikan berbagai kemudahan baik bagi peternak maupun bagi pemodal[4][5].

- Aris Sudianto, Hamzan Ahmadi, Alimuddin dalam jurnal yang diberi judul "Rancang Bangun Sistem Informasi Penjualan Sparepart Motor Pada Bengkel Vinensi Motor Berbasis Web Guna Meningkatkan Penjualan dan Promosi Produk" dapat ditarik kesimpulan bahwa tujuan membangun sistem informasi penjualan sparepart adalah agar pelanggan dapat melakukan pemesanan produk tanpa harus datang bengkel Vinensi Motor, pihak bengkel pun dapat mengatasi masalah 
pengolahan produk, pengolahan pemesanan sehingga memberikan kemudahan kepada konsumen untuk mendapatkan informasi tentang produk yang tersedia pada bengkel Vinensi Motor. Hasil dari penelitian ini adalah dengan diimplementasikan sistem informasi penjualan sparepart ini dapat digunakan sebagai sarana promosi penjualan yang dapat diakses dimanapun dan kapanpun, proses pembelian dapat secara langsung tanpa harus datang ke toko, serta dapat mempermudah proses transaksi pembelian produk, sehingga dapat meningkatkan penjualan dari bengkel Vinensi Motor itu sendiri[6][7].

\subsection{LandasanTeori}

\section{Aplikasi}

aplikasi adalah penerapan, penggunaan atau penambahan Dari pengertian diatas, dapat disimpulkan bahwa aplikasi merupakan software yang berfungsi untuk melakukan berbagai bentuk pekerjaan atau tugas-tugas tertentu seperti penerapan, penggunaan dan penambahan data[8].

Aplikasi yaitu suatu program yang siap untuk digunakan yang dibuat untuk melaksanankan suatu fungsi bagi pengguna jasa aplikasi serta penggunaan aplikasi lain yang dapat digunakan oleh suatu sasaran yang akan dituju. Menurut kamus computer eksekutif, aplikasi mempunyai arti yaitu pemecahan masalah yang menggunakan salah satu tehnik pemrosesan data aplikasi yang biasanya berpacu pada sebuah komputansi yang diinginkan atau diharapkan maupun pemrosesan data yang di harapkan[9].

\section{Penjualan}

Penjualan merupakan pembelian sesuatu (barang atau jasa) dari suatu pihak kepada pihak lainnya dengan mendapatkan ganti uang dari pihak tersebut. Penjualan juga merupakan suatu sumber pendapatan perusahaan, semakin besar penjualan maka semakin besar pula pendapatan yang diperoleh perusahaan[10].

Penjualan merupakan salah satu kegiatan yang dilakukan perusahaan untuk mempertahankan bisnisnya untuk berkembang dan untuk mendapatkan laba atau keuntungan yang diinginkan. Penjualan juga berarti proses kegiatan menjual, yaitu dari kegiatan penetapan harga jual sampai produk didistribusikan ke tangan konsumen[11].

\section{E-commerce}

E-Commerce sebagai bagian dari electronic bussines atau bisnis yang menggunakan electronic transmission. Secara umum E-Commerce dapat didefinisikan sebagai segala bentuk transaksi perdagangan barang atau jasa dengan menggunakan media elektronik. Media elektronik yang dibicarakan disini hanya difokuskan dalam hal penggunaan media internet. E-Commerce adalah proses pembelian, penjualan atau pertukaran 
produk, jasa dan informasi melalui jaringan komputer[12].

\section{Sembako}

Sembako adalah singkatan dari sembilan bahan pokok. Kesembilan bahan pangan yang termasuk dalam kategori pokok tersebut sudah dipatenkan oleh pemerintah dalam sebuah keputusan. Keputusan tersebut dikeluarkan oleh Kementrian Industri dan Perdagangan dengan Nomor Peraturan 15/MP P/Kep/2/1998 pada 27 Februari 1998[13].

\section{Database}

Definisi database menurut Jogiyanto adalah sekumpulan informasi atau data yang saling terkait satu dengan yang lainnya, yang dimana data itu tersimpan di luar komputer. Untuk memanipulasi data tersebut tentu dibutuhkan software tertentu atau software secara khusus[14].

Modern Database saat ini dikembangkan oleh suatu instansi melalui komputer dengan software agar pengguna komputer tersebut dapat mengakses data tersebut dengan mudah. Software yang dikembangkan untuk mengelola Database adalah DBMS (Database Management System). DBMS merupakan seperangkat program perangkat lunak yang kompleks yang mengontrol organisasi Database, manajemen, serta simpanan Database[15].
6. Android Studio

\section{studio}

Gambar 1 Logo Android Studio

Android Studio adalah Integrated Development Environment (IDE) pemrograman android resmi dari Google yang dikembangkan oleh IntelliJ. Android Studio memiliki banyak fitur yang memudahkan para pembuat program terutama programmer level dasar. Selain memiliki banyak fitur, Android studio juga memiliki banyak library yang sudah siap untuk digunakan[16].

7. Firebase

\section{Firebase}

Gambar 2 Logo Firebase

Merupakan suatu layanan yang digunakan untuk mempermudah para pengembang aplikasi dalam mengembangkan aplikasi. Firebase atau Baas (Backend as a Service). merupakan cara developer yang fokus mengembangkan aplikasi tanpa perlu memberikan effort yang besar[17].

\section{Metode Penelitian}

\subsection{Teknik Pengumpulan Data}

Metode pengumpulan data yang digunakan dalam penelitian ini diantaranya : 
1. Observasi

Melakukan observasi pada subjek penelitian yaitu target atau sasaran pengguna aplikasi dan objek penelitian yaitu produk-produk yang dijual di aplikasi e-sembako dimana hasil observasi ini digunakan sebagai bahan dalam perancangan dan pengembangan aplikasi.

\section{Wawancara}

Wawancara adalah suatu kegiatan penelitian yang dilakukan secara langsung dengan menggunakan pertanyaan-pertanyaan yang telah dipersiapkan dengan tujuan untuk mendapatkan informasi dari para informan/pengunjung Toko Rafa mengenai sistem penjualan,teknik pelayanan dll yang dilakukan pada Toko Rafa.

3. Studi pustaka

Pengumpulan data yang dapat mendukung penelitian ini yang diperoleh dari dari halaman website resmi, jurnal, buku, maupun artikel yang terkait dengan penelitian ini.

\subsection{Tahapan Penelitian}

Adapun tahapan-tahapan penelitian diantaranya adalah:

1. Tahapan pengumpulan data dan informasi yang dibutuhkan mengenai objek yang diteliti.

2. Tahap analisis

Tahapan ini dilakukan setelah data terkumpul semua, proses pengumpulan dilakukan secara intensif dan fokus khususnya pada software/perangkat lunak, agar bisa diimplementasikan sesuai dengan yang dibutuhkan oleh user/pengguna. kemudian dilakukan analisis dan hipotesa yang diajukan dan diuji kebenarannya melalui analisa tersebut.

3. Tahap desain dan proses

Pada tahap ini proses pembuatan lebih fokus pada desain pembuatan program perangkat lunaktermasuk dengan struktur data,arsitektur perangkat lunak, refresentasi antarmuka, dan procedur pengkodean.

4. Tahap experimen dan pengujian

Pada tahap pengujian ini dilakukan pengujian perangkat lunak secara logic dan fungsional. Untuk mengetahui apakah software yang dibuat telah sesuai dengan standar yang dibutuhkan atau tidak, serta mengetahui apakah masih ada kesalahan pada tahap sebelumnya.

5. Maintenance (pemeliharaan)

Software/perangkat lunak yang telah selesai dibuat melalui tahap demi tahap baik dari analisis sistem,desain, hingga pengujian akan diterapkan dan dilakukanpemeliharaan dengan cara pengecekan secara berkala.

Berikut tahapan penelitian yang disajikan dalam bentuk gambar sebagai berikut: 


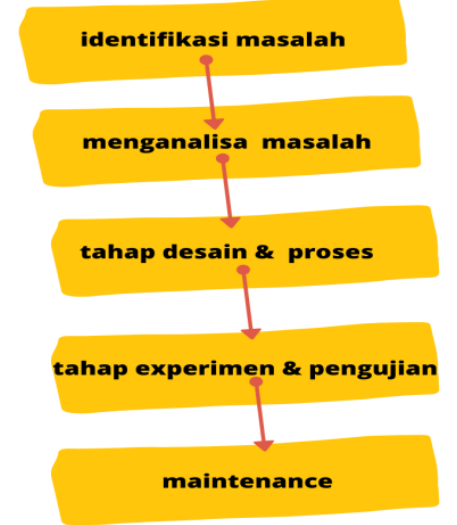

Gambar 3 Tahapan Penelitian

\subsection{Lokasi Penelitian}

Penelitian ini berlokasi di Toko Rafa Sawing Kelurahan Majidi Kecamatan Selong Kabupaten Lombok Timur Provinsi Nusa Tenggara Barat dan akan dilakukan mulai dari Bulan April sampai Bulan Juli 2021.

\section{Hasil Dan Pembahasan}

1. Tampilan Awal Aplikasi

Tampilan menu awal merupakan tampilan yang akan muncul pertama kali saat aplikasi dijalankan, pada menu ini akan menampilkan logo aplikasi, teks tentang Toko Rafa serta tombol menuju tampilan daftar akun ketika pengguna pertama kali menggunakan aplikasi E-sembako ini dan login aplikasi apabila sudah terdaftar sebagai pelanggan.

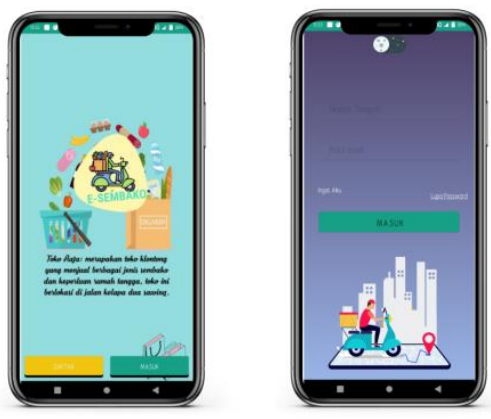

Gambar 4 Tampilan Awal Aplikasi

2. Tampilan Menu Produk

Menu ini berisi tampilan kategori dan list produk yang dijual oleh Toko Rafa pada aplikasi E-sembako ini yang terdiri dari tampilan gambar serta harga produk. Pada menu ini terdapat juga search bar atau cari produk untuk memudahkan pelanggan menemukan barang yang dicari, hal ini tentunya membuat waktu pelanggan dalam berbelanja dan memilih barang menjadi lebih efektif dan efisien.
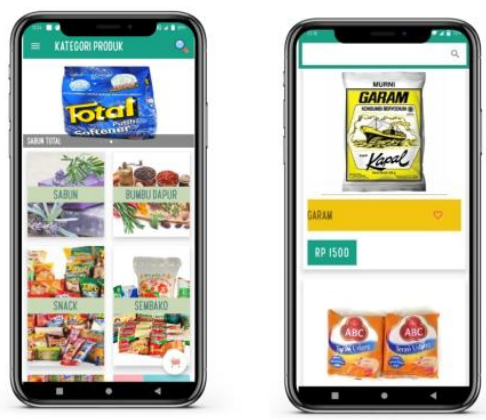

Gambar 5 Tampilan Menu Produk

3. Tampilan Detail Produk

pada menu ini berisi tampilan produk yang dipilih dengan tampilan gambar produk, harga produk, dan deskripsi singkat mengenai 
produk. Pada menu ini juga berisi tampilan untuk memberikan rating dan komentar mengenai produk serta tampilan menu tambah produk ke keranjang.

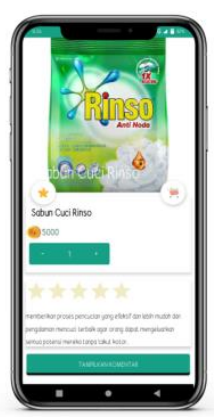

\section{Gambar 6 Tampilan Detail Produk}

\section{Tampilan Menu Keranjang Dan Pesanan}

Pada menu ini akan menampilkan produk yang telah dipilih dengan menyertakan tampilan gambar produk, harga produk, jumlah produk yang akan dipesan serta total harga pesanan. Pada menu ini juga berisi menu metode pembayaran yaitu dengan metode COD.
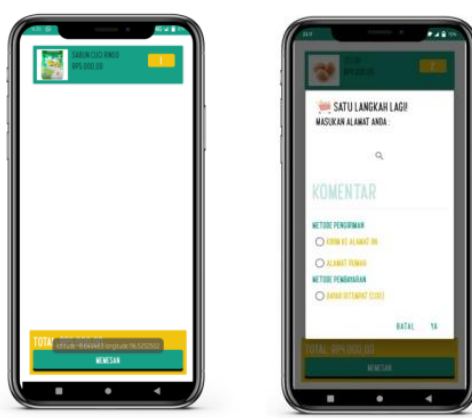

Gambar 7 Tampilan Menu Keranjang

\section{Tampilan Menu Admin Tambah Produk}

Menu ini hanya bisa diakses oleh admin di aplikasi server E-sembako. Cara admin untuk menambahkan kategori produk yaitu dimulai dari memasukkan nama produk lalu menekan tombol pilih gambar.pilih gambar atau pilih untuk menentukan gambar produk yang akan ditampilkan di menu kategori, Langkah yang sama juga diterapkan pada saat menambahkan list produk dari masing-masing kategori.
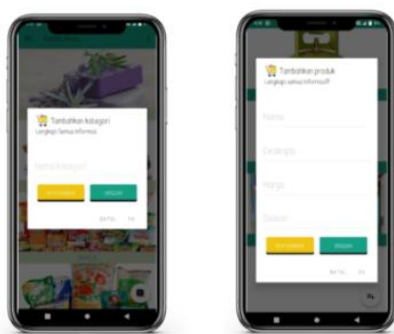

Gambar 8 Tampilan Menu Admin Tambah

Produk

6. Tampilan Kelola Pesanan Admin

Pada menu ini berisi tampilan edit pesanan, hapus pesanan, detail pesanan serta lokasi pemesan. Jika tombol Edit ditekan akan muncul form untuk mengubah status pesanan, tombol hapus digunakan untuk, tombol detail berisi detail pesanan pelanggan mulai dari nama produk, harga produk, jumlah pesanan dan juga diskon.
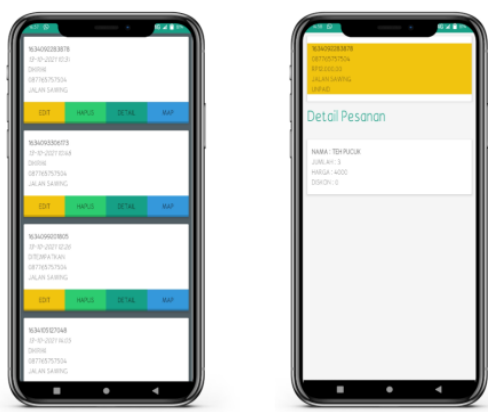
Gambar 9 Tampilan Menu Admin Kelola

Pesanan

\section{Kesimpulan}

Dengan selesainya hasil penelitian di Toko Rafa didapatkan kesimpulan mengenai "Rancang Bangun Aplikasi penjualan E-sembako Pada Toko Rafa berbasis Android." Adalah sebagai berikut:

1. Aplikasi ini dapat dimanfaatkan untuk mempermudah Toko Rafa dalam mengelola sistem penjualan dan pengelolaan produk.

2. Aplikasi E-sembako dapat dimanfaatkan konsumen untuk mencarai informasi megenai produk sembako pada Toko Rafa.

3. Aplikasi E-sembako ini diharapkan dapat meningkatkan omset pendapatan dari Toko Rafa.

\section{Daftar Pustaka}

[1] Ilham Firman Maulana, "Penerapan Firebase Realtime Database pada Aplikasi E-Tilang Smartphone berbasis Mobile Android," J. RESTI (Rekayasa Sist. dan Teknol. Informasi), vol. 4, no. 5, pp. 854-863, 2020, doi: 10.29207/resti.v4i5.2232.

[2] A. Abdul Aziz and F. S. Fajar K, "Perancangan Apikasi Mobile E-Commerce Berbasis Android Pada Toko Sembako Berkah Jaya Diera Covid-19," Pkm-P, vol. 4, no. 2 , p. 265,2020 , doi: $10.32832 / p k m-$ p.v4i2.753.
[3] M. R. Julianti, Z. Hakim, and T. Ardiyan, "Aplikasi Pedagang Sembako Online Berbasi Android," Acad. J. Comput. Sci. Res., vol. 3, no. 1 , pp. 11-15, 2021, doi: 10.38101/ajcsr.v3i1.330.

[4] A. Sudianto and M. Sadali, "Penerapan Aplikasi Berbasis Android Untuk Ternak Ayam Petelur Sebagai Wadah Untuk Menghubungkan Pemilik Modal Dengan Calon Peternak," Infotek J. Inform. dan Teknol., vol. 4, no. 1, pp. 87-95, 2021, doi: 10.29408/jit.v4i1.2999.

[5] S. M. Sudianto Aris, "Penerapan Media Pembelajaran Interaktif Pelajaran Bahasa Indonesia Berbasis Android Untuk Kelas Vii Madrasah Tsanawiyah Nahdlatul Wathan Ketangga Sebagai Upaya Untuk Peningkatkan Minat Belajar Siswa," Infotek J. Inform. dan Teknol., vol. 2, no. 2, pp. 5360, 2019.

[6] A. Sudianto and H. Ahmadi, "Rancang Bangun Sistem Informasi Penjualan Sparepart Motor Pada Bengkel Vinensi Motor Berbasis Web Guna Meningkatkan Penjualan dan Promosi Produk," vol. 3, no. 2, pp. 115-122, 2020.

[7] A. Sudianto and M. Wasil, "Penerapan Sistem Informasi Geografis dalam Pemetaan Sebaran Kasus Gizi Buruk Lombok Timur merupakan salah satu Kabupaten yang berada di Provinsi Nusa Tenggara Barat 
yang terletak di sebelah Timur Pulau Lombok

, Kabupaten Lombok Timur Gizi Buruk Malnutrisi," vol. 4, no. 2, pp. 142-150, 2021.

[8] L. Kasenda, X. Najoan, and A. M. Sambul, "Rancang Bangun Aplikasi Jasa Layanan Dokter Hewan," pp. 1-10.

[9] A. Juansyah, "Pembangunan Aplikasi Child Tracker Berbasis Assisted - Global Positioning System ( A-GPS ) Dengan Platform Android," J. IIm. Komput. dan Inform., vol. 1, no. 1, pp. 1-8, 2015.

[10] M. Mustopa, I. Junaedi, and A. Z. Sianipar, "Sistem Informasi Penjualan Dan Pengendalian Stock Barang Bangunan Pada Toko Bangunan Delima," J. Manajamen Inform. Jayakarta, vol. 1, no. 2, p. 105, 2021, doi: 10.52362/jmijayakarta.v1i2.447.

[11] F. F. Wati and U. Khasanah, "Sistem Informasi Penjualan Berbasis Web pada UD Dwi Surya Aluminium dan Kaca Yogyakarta," Paradig. - J. Komput. dan Inform., vol. 21, no. 2, pp. 149-156, 2019, doi: 10.31294/p.v21i2.6026.

[12] H. HELMALIA and A. AFRINAWATI, "Pengaruh E-Commerce Terhadap Peningkatan Pendapatan Usaha Mikro Kecil Dan Menengah Di Kota Padang," JEBI (Jurnal Ekon. dan Bisnis Islam., vol. 3, no. 2, p. 237, 2018, doi: 10.15548/jebi.v3i2.182.

[13] M. Fatchan and D. E. S. Wahyuningsih,
"Sistem Penjualan Sembako Pada Toko Srimukti Pasar Serang Kecamatan Serang Baru Berbasis Android," Vol. 10, vol. 54, no. 4, pp. 337-348, 2020, doi: $10.31857 / \mathrm{s} 0320930 \times 20040088$.

[14] I. Apryliyana, N. Yona, S. Munti, and H. Adeswastoto, "Perancangan Database System Informasi Pemetaan Trayek Bus Sekolah dan Halte Di Central Business District ( CBD ) Bangkinang ( Studi Kasus Di Dinas Perhubungan Kabupaten Kampar )."

[15] I. Mardiono, R. Fil'aini, and F. S. Didin, "Perancangan Sistem Basis Data Offline Dokumen Akreditasi Program Studi," Opsi, vol. 12, no. 2, p. 101, 2019, doi: 10.31315/opsi.v12i2.3153.

[16] Egy Muhammad Rianof, Bambang P. Adhi, and Z.E. Ferdi F. Putra, "Pengembangan Aplikasi M-Commerce Pada Toko Optik Menggunakan Android Studio," PINTER J. Pendidik. Tek. Inform. dan Komput., vol. 4, no. 2, pp. 15-18, 2020, doi: 10.21009/pinter.4.2.3.

[17] D. N. Ramadan, A. G. Permana, and H. Hafidudin, "Perancangan Dan Realisasi Mobil Remote Control Menggunakan Firebase," J. Elektro dan Telekomun. Terap., vol. 4, no. 1, p. 505, 2017, doi: 10.25124/jett.v4i1.997. 